\title{
A IMPORTÂNCIA DAS \\ METODOLOGIAS PARTICIPATIVAS \\ NAANÁLISE DO TRABALHO \\ TÉCNICO SOCIAL DO PROGRAMA \\ MINHA CASA MINHA VIDA
}

\author{
THE IMPORTANCE OF \\ PARTICIPATORY RESEARCH \\ METHODOLOGIES IN THE ANALYSIS \\ OF SOCIO TECHNICAL WORK OF THE \\ PROGRAM MINHA CASA MINHA VIDA
}

\author{
BARLETTO, Marisa \\ SOUZA, Rita Maria ${ }^{2}$ \\ CAMPOS, Mariana de Lima ${ }^{3}$
}

\section{RESUMO}

O presente artigo aborda a importância das metodologias participativas no trabalho de investigação e intervenção junto aos beneficiários do Programa Minha Casa Minha Vida, considerando a centralidade do Trabalho Técnico Social. O texto apresenta a proposta do Trabalho Técnico Social previsto na referida política pública, informa sobre o projeto de pesquisa e extensão desenvolvido junto aos conjuntos e destaca as estratégias metodológicas utilizadas. Discute os resultados, apontando as tensões entre a perspectiva assistencialista realizada no conjunto e a proposição do Trabalho Técnico Social, valorizando a opção metodológica de técnicas participativas de investigação para refletir a experiência dos benificiários e beneficiárias sobre a implementação do Programa Minha Casa Minha Vida. Conclui com reflexão sobre a importância da oportunidade do Programa de desenvolver uma prática pedagógica cidadã com a proposta do Trabalho Técnico Social.

Palavras-chave: Metodologia participativa. Habitação. Cidadania.

\section{ABSTRACT}

This article discusses the importance of participatory methodologies in research and in intervention with the beneficiaries of the Federal Housing Program Minha Casa Minha Vida, considering the centrality of Socio Technical Work. The article presents the Socio Technical Work proposal foreseen in the aforementioned public policy, informs about the research and outreach projects developed at the housing estates and highlights the methodological strategies used. The article also discusses the results pointing out tensions between the welfare perspective in the housing estates and the Socio Technical Work proposed, as a form of valuing participatory research methodologies techniques to reflect the experience of the beneficiaries concerning the implementation of the Federal Housing

1 Professora da Universidade Federal de Viçosa (UFV), Brasil. Doutorado em Educação pela Universidade Federal Fluminense (UFF), Brasil. E-mail marisabarletto@gmail.com

2 Colaboradora do Núcleo Interdisciplinar de Estudos de Gênero (NIEG) da Universidade Federal de Viçosa (UFV), Brasil. Especialização em Agroecologia pelo Instituto Federal do Espirito Santo (IFES), Brasil. E-mail rsouza136@hotmail.com

3 Aluna do curso de Mestrado em Administração Pública da Fundação João Pinheiro (FJP), Brasil. E-mail marianalcampos@gmail. com 
Program Minha Casa Minha Vida. The article concludes with a reflection about the opportunity provided by the program to develop a citizen pedagogical practice with the proposal of the Socio Technical Work.

Keywords: Participatory methodology. Housing. Citizenship.

\section{Introdução}

O presente trabalho foi elaborado a partir dos resultados do projeto de pesquisa e extensão ${ }^{4}$ desenvolvido junto aos beneficiários do Programa "Minha Casa Minha Vida”, em uma cidade de médio porte do interior de Minas Gerais. O projeto teve como principal objetivo pesquisar e problematizar os processos de representação e ressignificação dos beneficiários/as, enfatizando o modo como se relacionam com os eixos do trabalho social e com o espaço habitado. O objetivo desse artigo é informar sobre a metodologia participativa desenvolvida e destacar sua importância e coerência para a implementação do Programa Minha Casa Minha Vida (PMCMV). Ressaltamos que o projeto foi aprovado pelo Comitê de Ética da UFV (Parecer 424.433) e registrado na Plataforma Brasil (CAAE 16301513.6.0000.5153).

No PMCMV, o Trabalho Técnico Social (TTS) é um componente estratégico na atual proposta de política habitacional dirigida para classes populares. Segundo o Caderno de Orientaçáo do Trabalho Social (COTS, 2013), os novos instrumentos de gestão municipal têm apontado para a construção de políticas públicas com base em processos democráticos e através de novas formas de organização social. Essa tendência foi incorporada ao PMCMV através da proposição de trabalho social envolvendo mobilização e organização comunitária; geração de trabalho e renda e educação sanitária e meio ambiente (COTS, 2013). O investimento nesses eixos seria condicionante para a implementação do Programa cuja manutenção dependeria da autonomia dos beneficiários:

Uma premissa que norteia a concepção dos Programas é que a participação e o comprometimento dos beneficiários nos processos de decisão, implantação e manutenção dos empreendimentos, possibilitando a manifestação da população para que se produzam intervenções adequadas às suas necessidades e realidade sócio-cultural, permitindo afirmação da cidadania e transparência na aplicação dos recursos públicos. Em consonância com este princípio, nos Programas operacionalizados pela CAIXA, a participação da comunidade é entendida como um processo pedagógico de construçáo da cidadania e um direito do cidadão; e para assegurar que a sociedade, em especial, as famílias diretamente beneficiadas sejam envolvidas e ouvidas neste processo, é desenvolvido o Trabalho Técnico Social (COTS, 2013, p.4).

Considerando a citação, destacamos a relevância da participação dos beneficiários,entendida como condição central para a manutenção dos empreendimentos do Programa Minha Casa Minha Vida (PMCMV). Essa forma de envolvimento está assentada na perspectiva pedagógica de cidadania, como diz o texto, que por sua vez é uma demanda decorrente da crítica à implantação de políticas habitacionais anteriores, em que os conjuntos populares construídos eram distantes do local de trabalho de moradores, criando um deficit de transporte público e de outros serviços como abastecimento de água, sistemas de esgoto, luz, correios e segurança. (MARICATO, 1995). Com a proposição da participação e comprometimento dos beneficiários, estaria assegurada a 'voz' da população na realização do empreendimento. Segundo avaliação do Movimento Nacional de Luta pela Moradia, essa orientação de participação e controle social é resultado de conquistas do movimento social, que pode ser verificado desde a década de 1980, na luta pela implementação do Estatuto da Cidade e pelo Fundo Nacional de Habitação de Interesse Social. (MINISTÉRIO DAS CIDADES et al, 2011, p. 25).

4 Projeto "O Espaço Construído e o Espaço Habitado: o processo de representação e ressignificação dos/as beneficiárias/os do Programa Minha Casa Minha Vida sobre o Trabalho Social", financiado pelo CNPq e executado durante o período de outubro de 2012 a dezembro de 2014, pelo Núcleo Interdisciplinar de Estudos de Gênero - NIEG - da Universidade Federal de Viçosa - UFV. 
A citação do COTS (2013) também informa sobre a importância do papel dos beneficiários no processo de tomada de decisão para a implementação da política de habitação. Essa perspectiva, entendida como expressão do fortalecimento de práticas democráticas deliberativas, refere-se a um conjunto de procedimentos a serem debatidos numa esfera pública, que permitam aos beneficiários se posicionarem frente a outros atores sociais e políticos, apresentando seus argumentos.

Considerando os aspectos históricos, o Trabalho Técnico Social do PMCMV carrega uma reflexão importante sobre a dificuldade da população beneficiária em estar preparada ou não para discutir e se posicionar frente às instituiçóes que participam administrativa e financeiramente da implantação e implementação do Programa. A necessidade pedagógica explicitada no TTS é uma posição baseada no entendimento de que há no imaginário social uma noção de direitos invertida da prática de cidadania, ou seja, quando direitos são conjugados na gramática dos 'favores' concedidos pelo governo. Sendo consequência do caráter assistencialista, a noção de direitos como 'favores' do governo se assenta na naturalização das desigualdades sociais, esquecendo as dimensóes históricas e sociais que as determinaram. (MARICATO, 1995). No sentido inverso, o TTS propóe formas de controle social e participação através de instrumentos que desconstruam o imaginário social de direitos como 'favores'.

De acordo com o COTS (2013), o profissional que realiza o Trabalho Técnico Social se responsabiliza por promover formas de emancipação social e política dos grupos, criando condiçóes para práticas participativas e um grande amadurecimento da noçáo de cidadania. Todavia, tratando-se de um projeto pioneiro, não define claramente qual o perfil profissional exigido para essas tarefas, ou quais as exigências de qualificação específica. Nesse cenário, cursos de capacitação presencial e à distância têm sido oferecidos pelo Ministério das Cidades, por ONG's ou em parcerias público/privado. Segundo a publicação da Fundação AVSI, "Hoje, no Brasil, pode-se afirmar que há um conhecimento consolidado acerca do trabalho social realizado de suporte às famílias beneficiadas diretamente com as obras de urbanização" (s/d, p. 5).

A perspectiva do empoderamento emerge da proposição de realização do Trabalho Técnico Social (TTS) presente nas diretrizes das intervençóes habitacionais do âmbito do Ministério das Cidades, assim como as açóes do Programa Minha Casa Minha Vida. Essa proposição assume um caráter de intervenção na realidade vivenciada pelos moradores, incentivando a participação e inserção social das famílias em articulação com as demais políticas públicas, buscando a efetivação dos direitos sociais e apropriação do espaço com vistas a melhorias na qualidade de vida e sustentabilidade dos bens e serviços implantados. Dessa forma, a proposta do Trabalho Técnico Social se apoia em princípios que colaboram para o reconhecimento dos beneficiários enquanto sujeitos coletivos e que formam os pontos basilares para a gestáo democrática das intervençóes e estreitamento dos laços sociais. No entanto, como mostra o trabalho realizado, percalços de variadas naturezas compóem o cotidiano das famílias que residem nos conjuntos, apontando, portanto, algumas fragilidades no que se refere à efetividade do trabalho social proposto. 


\section{O Projeto}

O Projeto aqui apresentado teve como objetivo desenvolver uma análise e discussão sobre o trabalho social no sentido de compreender a representação dos beneficiários do PMCMV, de uma cidade no interior de Minas Gerais, sobre o significado de participaçáo social, mobilização e organização, educação sanitária e ambiental e o significado do termo habitar. Para isso, recorremos à metodologia participativa proposta pelas ciências sociais, procurando compreender a construção de vida em comum dos moradores do PMCMV.

Tais consideraçóes iam ao encontro dos pressupostos apresentados nos documentos que orientaram a elaboração e execução do empreendimento PMCMV, no que tange à orientação da necessidade de realizaçáo de métodos participativos que viabilizem a sustentabilidade do trabalho social.

Consideramos que essa proposição política de construção do empreendimento é uma novidade enquanto política de habitação e, sendo assim, demanda avaliação de forma a aprimorar técnicas e métodos de participação levando os moradores a construir uma vida social. Nesse sentido, propusemos com esse projeto a avaliação do processo participativo recomendado pelo PMCMV, através do COTS, enquanto pilar da sustentabilidade do trabalho social e para além disso, do empoderamento dos sujeitos coletivos na construçáo do espaço social.

Vale ressaltar que o termo empoderamento emerge na década de 1970 com uma conotação política defendida pelos movimentos feministas e pelo movimento negro. Esses movimentos se constituíram como espaço importante de mobilizaçáo em torno da defesa e da garantia da igualdade de direitos. (HOROCHOVSKI, 2006). O empoderamento está ligado ao conceito de autonomia. Nesse sentido, na medida em que são tecidos espaços participativos de reflexão e organização com os beneficiários, o grupo ressignifica suas relaçóes e abre possibilidades de mobilização, marcando e demarcando posição na sociedade e reivindicando direitos e políticas que levem em conta seus desejos e aspiraçóes.

Entendemos que o processo participativo suscita o sujeito a refletir sobre sua condição no espaço. Através dessas compreensóes e experiências, conseguem se apropriar do espaço, transformando-o em lugar, no sentido dado por Milton Santos (2002).

Considerando que a política que norteia o PMCM prioriza grupos de alta vulnerabilidade e que esses hoje são preponderantemente famílias chefiadas por mulheres, a categoria gênero se impóe como perspectiva de análise dos eixos que ancoram o trabalho social e, consequentemente, a sustentabilidade dessa política habitacional. $\mathrm{Na}$ primeira aproximação da experiência do PMCMC na cidade em questão, percebemos as dificuldades enfrentadas por essas mulheres chefes de família em lidar com o reordenamento das relaçóes de poder imposto pelo próprio Programa que, ao definir a mulher como detentora do patrimônio, desorganiza o poder patriarcal familiar.

$\mathrm{O}$ objetivo geral do projeto foi investigar os processos de representação e ressignificação dos beneficiários dos condomínios do PMCMV, a partir dos três eixos do trabalho social (mobilização e organização comunitária, educação sanitária e ambiental e geração de trabalho e renda), refletindo como os processos participativos modificam o espaço construído em espaço habitado. Os principais objetivos específicos foram: (i) analisar a representação dos sujeitos das instituiçôes parceiras e dos/as beneficiários/as sobre o processo participativo na história da organização dos empreendimentos; (ii) analisar a representação dos beneficiários sobre os três eixos do trabalho social - mobilizaçáo e organização comunitária, educação sanitária e ambiental, geração de trabalho e renda; 
(iii) refletir coletivamente com os beneficiários sobre o cotidiano nesses loteamentos criando um espaço de mobilização sobre temas e objetos que afetam a comunidade; (iv) compreender os processos de ressignificaçáo realizados pelos beneficiários sobre o espaço e os elementos que transversalizam os três eixos do trabalho social; (v) analisar como a categoria gênero transversaliza os processos de ressignificação.

Destacamos a importante participação de estudantes da Universidade Federal de Viçosa na execução do trabalho proposto. Estiveram envolvidos estudantes dos seguintes cursos de graduação: Arquitetura, Ciências Sociais, Geografia, Engenharia Ambiental, Enfermagem e Pedagogia. Além desses, também participaram do trabalho técnicas das áreas de Gestão Ambiental e Economia Doméstica. As professoras coordenadoras eram vinculadas às áreas de Educação, Saúde Pública, Arquitetura e Engenharia Ambiental.

$\mathrm{Na}$ cidade investigada, o empreendimento de casas populares pelo Programa Minha Casa Minha Vida abrange, atualmente, três conjuntos habitacionais ${ }^{5}$ : Conjunto 1, Conjunto 2 e Conjunto 3. O Conjunto 1 foi o primeiro a ser construído e foi entregue em 16 de setembro de 2011, contendo 132 unidades habitacionais, divididas em 13 quadras. As casas são de alvenaria, compostas de dois quartos, sala, cozinha, banheiro e área de serviço. Do total de 132 famílias, 91,7\% são chefiadas por mulheres, sendo que $64,42 \%$ possuem ensino fundamental incompleto e $27,2 \%$ se ocupam do trabalho doméstico. Dentre as famílias beneficiadas, $63,3 \%$ possuem renda familiar de até $1 \mathrm{SM}$ e $54,5 \%$ recebem algum tipo de benefício do governo. Quanto ao tamanho dessas famílias, $68,2 \%$ são compostas por 3 a 5 pessoas e $25,7 \%$ possuem 2 filhos.

O Conjunto 2 foi entregue em 04 de julho de 2012, contendo 123 unidades habitacionais. Entre os critérios de seleção para os beneficiários/as, prioritariamente, estava a populaçáo idosa e/ou portadora de necessidades especiais. Assim como o conjunto Coelhas, as casas são de alvenaria, compostas de dois quartos, sala, cozinha, banheiro e área de serviço. Do total de 123 famílias, $80,4 \%$ são chefiadas por mulheres, das quais $66,6 \%$ possuem ensino fundamental incompleto e $21,1 \%$ se ocupam do trabalho doméstico. Dentre as famílias beneficiadas, $62,60 \%$ possuem renda familiar de até $1 \mathrm{SM}$ e $61,79 \%$ recebem algum tipo de benefício do governo. Quanto ao tamanho dessas famílias, 54,47\% são compostas por 3 a 5 pessoas e 28,45\% possuem 1 filho.

O Conjunto 3 foi entregue em 30 de março de 2012, contendo 80 unidades habitacionais distribuídas em cinco prédios de quatro andares, com dezesseis apartamentos cada. Essas moradias são compostas de dois quartos, sala, cozinha e banheiro, totalizando $42 \mathrm{~m}^{2}$ de área construída. Dois dos blocos contam com área coberta para uso coletivo. Do total de 80 famílias, $81,25 \%$ são chefiadas por mulheres, sendo que $28,75 \%$ possuem ensino fundamental incompleto e $41,25 \%$ se caracterizam como donas de casa/do lar. Dentre as famílias beneficiadas, $84 \%$ possuem renda familiar de até 1 SM e $60 \%$ recebem algum tipo de benefício do governo. Quanto ao tamanho dessas famílias, $58,75 \%$ são de até 5 pessoas residindo no mesmo apartamento.

\section{Metodologia participativa}

A escolha desta metodologia vai ao encontro das diretrizes do PMCMV. Conforme definido por Gomes et al. (2001), o conceito de participaçáo, no âmbito dos processos

5 Dados obtidos através dos Projetos de Trabalho Técnico Social (PTTS) dos conjuntos habitacionais. Os números se referem à frequência relativa encontrada através do levantamento social das famílias beneficiadas. 
de diagnósticos e planejamentos participativos, pressupóe divisão de poder no processo decisório, passando pelo controle das partes sobre a execução e a avaliação dos resultados pretendidos. Ou seja, participar, nesse caso, é tomar parte das decisóes e ter parte dos resultados.

Segundo Verdejo (2006), além do objetivo de impulsionar a autoanálise e a autodeterminação de grupos comunitários, o propósito do DRP é a obtenção direta de informação primária ou de "campo" na comunidade, por meio de grupos representativos de seus membros, até chegar a um autodiagnóstico sobre o estado dos seus recursos naturais, sua situação econômica e social e outros aspectos importantes para a comunidade de maneira ágil e oportuna.

Segundo Coelho (2005), o profissional que trabalha com metodologia participativa é um dos agentes do processo de conhecimento e exerce a função de criar espaços propícios à realização de formas interativas e discursivas, espaços de discussão e de negociação, cuja coordenação deve facilitar a alternância de responsabilidade na condução das propostas que vão surgindo durante o desenvolvimento da técnica. Nesse sentido, o papel daquele que conduz o processo de intervençáo em trabalhos que envolvem uma ação participativa é o de estabelecer o diálogo e a aprendizagem mútua com todos os sujeitos envolvidos na ação. Tais escolhas condizem com os pressupostos apresentados nos documentos que orientam a elaboração e execução dos empreendimentos do PMCMV, no que tange à necessidade de realizaçáo de métodos participativos que viabilizem a sustentabilidade do trabalho social.

Assumida essa escolha teórico-metodológica, recorremos a um conjunto variado de campos disciplinares e temáticos, procurando compreender as esferas de manifestação de sentidos e sentimentos que concorreram por influenciar a construção da vida em comum dos moradores do PMCMV. Nessa perspectiva, a reflexão se deu em torno de categoriaschave à interpretação de processos, como: mobilização, experiência, memória, organização comunitária, ação social, dominação, marginalidade, exclusão e inclusão social, dentre outras que acreditamos concorrerem no exercício de empoderamento do grupo.

Segundo Drumond, Giovanetti e Queiroz (2009), o mediador das técnicas participativas precisa compreender a realidade social e cultural dos participantes e respeitar as tradiçóes locais das comunidades onde são desenvolvidos os trabalhos. (p.33). Dada a delicadeza política, social e cultural do uso de metodologias participativas, houve um grande cuidado com a escolha e capacitação dos estudantes que atuaram no projeto. Os alunos envolvidos nesse trabalho foram capacitados por meio de oficinas sobre temas que seriam pertinentes à execuçáo desse projeto: (i) história do feminismo: da primeira onda, passando pela década de 1970 até o surgimento da categoria gênero; (ii) gênero e identidades; (iii) entrada a campo; (iv) metodologias participativas; (v) políticas públicas e direitos humanos, sexuais e reprodutivos; (vi) violência contra a mulher; (vii) grupo focal; (viii) elaboração de relatorias. Foi também realizado, de forma continuada, grupos de estudos abordando os seguintes temas: (i) participação social; (ii) saneamento e educação ambiental; (iii) trabalho e renda; (iv) violência contra a mulher; (v) infraestrutura e percepção social do espaço. Com relação às técnicas participativas que seriam utilizadas em campo, foram realizadas oficinas específicas com objetivo de capacitar os alunos, além do treinamento continuado durante o período que antecedeu o trabalho nos conjuntos. A entrada no campo também exigiu uma competência que não se ensina: a construção de relaçóes de confiança com os moradores (DRUMOND, GIOVANETTI\& 
QUEIROZ, 2009). Sem regras muito claras de como estabelecer e dar consistência a esse processo, apostamos na sensibilidade dos estagiários e estagiárias e investimos na formação e capacitação para os temas citados: a problematização da ética no trabalho e a problematização política das desigualdades de classe, gênero e raça. Outro elemento técnico foi a utilização da Caminhada Transversal e Observação Participante como estratégia de aproximar estudantes e moradores, além de favorecer a criaçáo de vínculos sociais solidários. Todo o material produzido durante esse período foi transcrito para o caderno de campo. Cabe ainda ressaltar que já no processo seletivo de estudantes foi definido um perfil que tivesse potencial para o trabalho nessa perspectiva metodológica.

Foram utilizadas sete técnicas participativas, sendo duas com o objetivo de imersão, formação de vínculo e compreensão do cenário social; quatro atividades temáticas em cada conjunto habitacional, em que foram discutidos elementos que perpassam pelos eixos do trabalho social, além do processo de representação local e relação com as instituiçóes governamentais e náo governamentais; entrevistas semiestruturadas para detalhamento da memória da implementação dos conjuntos, da percepção das comunidades no entrono dos conjuntos e para aprofundamento de algumas informaçóes.

As técnicas participativas utilizadas foram:

- Observação participante: primeira técnica utilizada para imersáo no campo e foi realizada por meio de visitas regulares realizadas aos conjuntos habitacionais quando foram desenvolvidas conversas informais e, como base em seus resultados, foram elaborados os diários de campo. Nesses diários, constavam anotaçôes e descriçóes realizadas pela equipe referente às percepçóes sobre os conjuntos e experiências em campo para posterior produçáo de relatorias e reflexóes acerca da realidade, a partir de onde foi possível, também, identificar e analisar os elementos de participação popular nos conjuntos.

- Caminhada Transversal: constituiu-se também em uma técnica para imersão no trabalho de campo e permitiu obter informaçóes e conhecimento sobre os diversos aspectos ligados à realidade local. Através da caminhada, foram percorridos nos conjuntos os espaços pré-determinados pelos moradores, onde fizeram a apresentaçáo do local em que vivem, a partir de suas próprias percepçóes e representaçóes da área e da realidade presente. A realizaçáo da técnica permitiu que a equipe conhecesse o lugar e que os moradores e moradoras observassem o lugar e o dia a dia com outro olhar.

- Mapa Falado: essa técnica foi realizada por meio de desenho representativo do espaço dos conjuntos habitacionais, elaborado pelos próprios moradores. A cada elemento acrescentado no desenho, era explorado o conhecimento e opiniáo do grupo. Conforme Dumond, Giovanetti e Queiroz (2009), "o processo de construção de um mapa e as discussões agregadas a ele fornecem base de análise sobre aspectos ambientais e sociais da área” (p.47). Assim, foi uma ferramenta que permitiu que moradores refletissem sobre o empreendimento, o ambiente em que vivem e as formas de ocupação da área.

- Diagrama de Venn: o tema trabalhado através do Diagrama de Venn foi sobre as relaçôes institucionais. A discussão sobre as relaçôes sociais se deu por meio de um diagrama composto por círculos de tamanhos diferentes, dispostos de forma a representar as relaçôes existentes entre moradores e alguma instituição (formal ou informal) da sociedade ou mesmo pessoas que tenham importância para o conjunto, ou seja, aquelas com capacidade efetiva de atingir seus objetivos. 
Quanto maior o acesso a tais instituiçóes ou pessoas, maior o tamanho do círculo. Já a distância entre os círculos representou a relação entre os referidos grupos, ou seja, quanto mais próximo, maior a parceria e/ou colaboração. Devido ao grau de dificuldade encontrado no desenvolvimento dessa técnica nos conjuntos, optamos por utilizar os círculos com apenas três tamanhos (pequeno, médio e grande) e cores diferentes para facilitar a visualização do diagrama. Foi possível identificar a representação dos beneficiários sobre seu ambiente interno e externo, ao mesmo tempo em que puderam refletir sobre como se dão as parcerias existentes entre os grupos e instituiçóes formais e informais que atuam na realidade dos conjuntos.

- Diagrama de Fluxo: com essa técnica, foram trabalhados os problemas relacionados ao saneamento básico, por meio da tática de identificaçáo de causas e consequências de um problema. O primeiro passo foi discutir com o grupo o tema do saneamento básico do conjunto e, a partir daí, os problemas identificados foram escritos em tarjetas. As causas foram posicionadas acima do problema e as consequências abaixo. Conforme o prosseguimento da discussão, novas tarjetas foram compondo o diagrama permitindo que fossem visualizadas inter-relaçóes, fatos e problemas. Ao final da técnica, os participantes foram instigados, a partir de suas próprias reflexóes, a discutirem de que forma poderiam resolver as situaçôes (causas) e por quais caminhos buscar as possíveis soluçóes.

- Grupo Focal: em cada conjunto habitacional, os moradores foram convidados a participar da reunião onde foi tratado o tema "organização e participação social". O objetivo foi produzir informaçóes sobre quais as questôes - boas e ruins sobre a convivência coletiva, o modo como os participantes se organizavam para resolver as questóes e problemas comuns do conjunto, sobre a criação de associações de moradores, a história da construção dessas açôes comunitárias e análise das principais dificuldades. Ao promover o debate, o tema abordado foi problematizado mais coletivamente. No desenvolvimento da técnica, o tema abordado nos três conjuntos se configurou como um espaço de troca de experiências, percepçóes, angústias e reflexóes.

- Entrevistas semiestruturadas: foram realizadas entrevistas com os beneficiários indicados por moradores como pessoas-chave na história da implementaçáo de cada conjunto, como também com representantes das instituiçóes envolvidos no processo de implementação do Programa. Essas entrevistas tiveram como objetivo construir uma memória de cada conjunto, com o foco no processo de discussão e participação dos beneficiários no projeto de cada conjunto do PMCMV. As entrevistas semiestruturadas também foram utilizadas como técnica de produção de informação sobre a percepção dos conjuntos junto aos moradores que residiam nos bairros e áreas localizadas no entorno desses conjuntos, a fim de obter um retrato mais completo da realidade dos conjuntos habitacionais no município. Além disso, foram utilizadas entrevistas para aprofundar algumas questóes relativas às questóes de saneamento básico e organização social dos moradores.

Em termos quantitativos, nos conjuntos 1, 2 e 3, participaram do Grupo Focal 09 pessoas, 07 pessoas e 10 pessoas respectivamente. Do Diagrama de Venn participaram 04 pessoas, 08 pessoas e 13 pessoas respectivamente. Do Mapa Falado participaram 07, 08 e 15 pessoas. Do Diagrama de Fluxo participaram 04, 11 e 
10 pessoas. Na Caminhada Transversal, no Conjunto 3, participaram 13 pessoas num grupo e 17 pessoas em outro grupo. Nos Conjuntos 1 e 2 não foi realizada Caminhada Transversal porque os moradores não gostaram muito da proposta e decidimos não realizá-la. Como as conversas informais da Observaçáo Participante nesses conjuntos foram muito produtivas - envolvendo cerca de 90 pessoas em média em cada Conjunto - não houve prejuízo à pesquisa.

Dentre as dificuldades na realização dos trabalhos, a principal foi a falta de motivação por parte dos moradores e moradoras, fazendo com que a mobilização para as oficinas fosse prejudicada. A dificuldade em acesso a documentos e a negativa em fornecer entrevista por parte das construtoras e agentes públicos também foram obstáculos na elaboração da história dos conjuntos.

\section{Os processos participativos nos Conjuntos}

Antes da realização das técnicas de Diagnóstico Rápido Participativo, houve um intenso trabalho de sensibilização e mobilização dos moradores para participarem e contribuírem nas oficinas. Foi um trabalho de incentivo com os moradores para participarem dos grupos de discussão.

A impossibilidade de realizar o DRP em local público fez com que combinássemos os encontros dos Conjuntos1 e 2 na casa de moradoras. Sabemos a importância metodológica de se utilizar espaços públicos (associaçóes, igrejas, etc.) para evitar algum tipo de constrangimento por parte de moradores. No entanto, como não existia esse tipo de local no conjunto, optamos em realizar as técnicas nas residências.

Além do processo de mobilização, as decisões sobre o local, a data e o horário para realização da atividade foram feitas de forma coletiva. O grupo de estudantes responsável pela condução do encontro se reunia com moradores para discutir e organizar a programação do mesmo. Como era frequente a presença das mulheres com seus filhos, sempre havia um monitor encarregado de realizar atividades educativas com as crianças no intuito de evitar a exposição delas aos assuntos tratados, assim como garantir a tranquilidade necessária para que as mães pudessem participar.

A participação nos grupos foi quase que exclusivamente das mulheres. Assim como geralmente acontece nos trabalhos com esse caráter, algumas pessoas ficavam à vontade para se expressar, enquanto outras permaneciam em silêncio. Todas as participaçóes foram tratadas com igual respeito. Além de críticas e reflexóes, o trabalho foi conduzido, respeitando o tempo e a capacidade de análise dos moradores e moradoras. $\mathrm{O}$ mediador incentivava a reflexão sobre a realidade dos condomínios, a relação com as políticas públicas de apoio e os problemas vivenciados no cotidiano. As participantes foram encorajadas a tomarem posiçóes e pensarem formas coletivas de encaminhar as reclamaçóes. Foi incentivada a formulação de propostas concretas e possíveis de serem realizadas. Nesse sentido, as reclamaçóes generalizadas sobre os conjuntos eram sempre trazidas para a realidade do grupo presente e discutidas as estratégias necessárias e que estivessem no âmbito de resolubilidade dos presentes.

Elas criticavam a atuação de alguns órgãos como o Programa Saúde da Família (PSF), Correios, serviço de água e esgoto do município (SAAE) e, principalmente, a Prefeitura, relacionando as responsabilidades que cabem a esses órgáos aos problemas que fazem parte da realidade dos moradores. Discutiram também a escassez de horários de 
ônibus coletivo disponível e os problemas estruturais presentes em algumas casas, por exemplo.

No Mapa Falado, por exemplo, as moradoras sugeriram colocar muitas crianças e muitos cachorros, uma vez que o número é muito alto no conjunto. Outra coisa que elas desenharam foi muito mato em frente às casas, associando a falta de prestação de serviço por parte da prefeitura. Quanto à iluminação pública, decidiram desenhar postes sem luz, reafirmando que muitos não apresentam luz elétrica, tendo vários pontos que são completamente escuros, o que pode ser perigoso para quem transita por lá à noite. Já em relação às casas, algumas moradoras relataram problemas estruturais, como rachaduras nas paredes, dizendo que se sentem inseguras com esse fato e que, infelizmente, é a realidades delas.

Alguns participantes conseguiram analisar as situaçóes-problema que eram debatidas nas reunióes. Alguns pontos como o parquinho destruído e a falta de lazer, responsabilizando a prefeitura, que náo cumpria o seu papel de prestar os serviços públicos. Outros aspectos abordados foram as questóes envolvendo saneamento básico como a água e o lixo, afirmando que há poucos recipientes (conteiners) para depositar esses resíduos e que isso pode trazer várias consequências uma vez que havia um grande número de animais e crianças no condomínio e, também, favorecendo a proliferação de insetos, escorpióes, ratos e outros animais, afetando a saúde dos moradores. No conjunto 2, foi abordado o problema da caixa de gordura presente em cada casa. Os moradores falaram que a limpeza ocorre a cada seis meses. Outros problemas também nesse âmbito foram indicados, mas foi explicitada a satisfação com o serviço do SAAE.

\section{Resultados}

A finalidade do Projeto apresentado náo foi fazer o monitoramento do trabalho realizado pelas técnicas e técnico do PMCMV. Também não foi avaliar as ações do poder público municipal e/ou das outras instituiçóes envolvidas na implantação e implementaçáo do Programa. O objetivo central foi compreender o processo de representação dos beneficiários do PMCMV sobre Trabalho Técnico Social. Através do conjunto de técnicas participativas de investigaçáo-ação, compreendemos que a representação do TTS para os beneficiários do PMCMV da cidade em questão esteve centrada no assistencialismo, seja valorizando ou desvalorizando o TTS. As referências dos moradores sobre o Trabalho Técnico Social estiveram organizadas em torno da "ajuda" aos moradores e moradoras, no sentido de "levar" a eles oficinas (sabão, manicure). Além disso, as dificuldades do TTS foram atribuídas a uma suposta incapacidade dos moradores de colaboração e encaminhamentos coletivos, seja por suas origens de classe ou de gênero, e também atribuídas a uma suposta incompetência do técnico ou técnica social devido à falta de resultados e/ou falta de soluçóes para os problemas nos conjuntos, seja de ordem estrutural, financeira ou social.

Nas diferentes atividades desenvolvidas pelo Projeto, os beneficiários informaram que foram poucas as reunióes com os técnicos do PMCMV, cuja pauta tratava da convivência dos moradores. Na maioria das reunióes, enfatizava-se mais questóes operacionais de cursos ou questóes administrativas com o banco ou com a construtora. Segundo os entrevistados, nas reuniōes, falava-se "sempre das mesmas coisas". 
Mesmo considerando essas pautas, as dificuldades apontadas tinham muito mais a ver com o não cumprimento das condiçóes para implantação do PMCMV - como transporte, serviços de saúde, escolas, etc. - do que com as propostas do TTS. Havia, nas narrativas, uma explícita referência ao sentimento de terem sido "jogados nos conjuntos".

Analisamos que a percepção de beneficiários sobre a distância entre as condiçóes de infraestrutura vislumbradas na proposta e a realidade encontrada nos conjuntos teve forte determinação na representação do TTS como assistencialista. A imagem de que foram "jogados nos conjuntos" foi acentuada com o fim do contrato dos técnicos sociais, que teve duração de um ano.

Entendemos que o TTS é um projeto inovador do ponto de vista das políticas públicas e, assim, precisa amadurecer enquanto prática social e pedagógica. Nesse sentido, avaliações de experiências realizadas são importantes, como o trabalho de Francesco di Villarosa (MINISTÉRIO DAS CIDADES, 2011), que realizou estudos de caso em algumas capitais brasileiras, focando os componentes sociais dos projetos e também a dimensão urbanístico-arquitetônica e a institucional.

Villarosa destaca a importância de equipes sociais qualificadas e multidisciplinares e, por sua vez, a importância dessas equipes desenvolverem açóes a partir de políticas sociais locais, ou seja, "as equipes sociais não devem conduzir determinadas açóes de forma isolada das políticas sociais, mas o programa pode ser o eixo catalisador das diferentes políticas" (MINISTÉRIO DAS CIDADES, 2011, p.12).Segundo o consultor, normalmente, as açóes de geração de trabalho e renda tendem a ser pontuais, com dificuldades de alcançar escala e sustentabilidade. "É uma área em que é preciso trabalhar com diagnósticos mais rigorosos das vocaçôes e dos mercados locais." (idem).

Villarosa analisa que existem alguns pontos críticos do Trabalho Social, dos quais destacamos dois: a forma de efetivar a intersetorialidade, ou seja, que "não é o trabalho social que promove a intersetorialidade, esta já deve ser parte do programa de governo da Prefeitura." (MINISTÉRIO DAS CIDADES, 2011, p.13). O segundo ponto crítico que destacamos do texto de Villarosa refere-se à necessidade de um "salto de qualidade no sentido de uma maior profissionalização do trabalhador social. [...] Em muitos casos, o TS se limita a criar um ambiente favorável para as açóes de urbanização" (Idem, p.14).

Analisando o TTS do MCMV na cidade investigada, observamos que nenhum dos apontamentos feitos por Villarosa estiveram presentes nas açóes nos conjuntos. Não havia uma equipe multidisciplinar, apenas um técnico agindo isoladamente em cada conjunto. Não havia políticas sociais no município a serem catalisadas pelo TTS. Não houve diagnósticos rigorosos das vocaçóes e dos mercados locais. A intersetorialidade é inexistente enquanto gestão municipal. Por fim, havia uma grande dificuldade de técnico e técnicas em tecer práticas participativas e propor capacitaçóes de gestão democrática, como previsto no TTS.

\section{Conclusóes}

Tal cenário reflete a dificuldade de milhares de municípios brasileiros em desenvolverem tais açóes, já que formas de controle social e processos de gestão participativa ainda são desconhecidos e tudo está para ser desenvolvido. Destacamos, não uma suposta insuficiência do trabalho do técnico social, mas a necessidade de 
instrumentos que incidam sobre os municípios para proporcionar as mínimas condiçóes para que o TTS seja desenvolvido.

Apesar de todas as dificuldades enfrentadas pelos técnicos sociais, pela ausência de lastro político e administrativo de práticas participativas, pela inexistência de movimentos sociais que alavancassem tais açōes formativas e democráticas, foi possível vislumbrarmos o início de formas próprias de organização social de beneficiárias em um dos conjuntos. Isso aponta que a obrigatoriedade do projeto de TTS nos conjuntos do PMCMV foi uma decisão acertada, mas que precisa de revisóes quanto à definição das competências de seus profissionais, da ação intersetorial e práticas pedagógicas com metodologias participativas.

\section{Referências}

COELHO, France Maria Gontijo. A arte das orientações técnicas no campo: concepções e métodos. Viçosa: Ed. UFV, 2005.

COTS.Caderno de OrientaçãoTécnico Social. Gerência Nacional Gestão Padronização e Normas Técnicas (GEPAD), Superintendência Nacional Assistência Técnica e Desenvolvimento Sustentável (SUDES), Caixa Econômica Federal.Brasília, 2013.

DRUMOND, Maria Auxiliadora; GIOVANETTI, Lívia; QUEIROZ, Artur; e colaboradores. Técnicas e Ferramentas Participativas para a Gestão de Unidades de Conservação. 2a Ed. Brasilía: GTZ. 2009.

FUNDAÇÃO AVSI. Trabalho Social em Programas e Projetos de Habitação de Interesse Social. Manual temático Conhecimento e planejamento integrados. Ministério das Cidades; Aliança das Cidades. Fonte:www.avsiusa.org/docs/pdf/Brazil-Integ-Urban-Manual2-CSO-pt.pdf. Acessado em 30 de outubro de 2014.

GOMES, M.A.O. et al. Diagnóstico Rápido Participativo (DRP) como mitigador de impactos socioeconômicos negativos em empreendimentos agropecuários. In: BROSE, M. (Org.). Metodologia Participativa: uma introdução a 29 instrumentos. Porto Alegre: Tomo Editorial, 2001. 312p.

HOROCHOVSKI, R. R. Empoderamento: definições e aplicações. Anais 30 Encontro Anual da ANPOCS. Caxambu, 2006. Fonte: http://www.anpocs.org/portal/. Acessado em 2013.

MARICATO, E. Metrópole na periferia do capitalismo. Legalidade, Desigualdade e Violência. São Paulo: Hucitec, 1996.

MINISTÉRIO DAS CIDADES, SECRETARIA NACIONAL DE HABITAÇÃO ALIANÇA DE CIDADES, BANCO MUNDIAL. Trabalho Social e Intervenções Habitacionais. Reflexões e aprendizados sobre o Seminário Internacional. Brasília, 2011.

SANTOS, Milton. A Natureza do Espaço: Técnica e Tempo, Razão e Emoção. São Paulo: Editora da Universidade de São Paulo, 2002.

VERDEJO, M. E. Diagnóstico Rural Participativo: um guia prático. Secretaria da Agricultura Familiar - MDA. Ascar - Emater RS, 2006. 61p. 